Marques, Cláudia Lima - Contratos no Código de Defesa

Martins Costa, Judith - Crise e Modificação da Idéia de Contrato no Direito Brasileiro, in Direito do Consum dor, 3, Editora Revista dos Tribunais, São Paulo, 1992. Miranda, Custódio Piedade Ubaldino - Interpretação e Integração dos Negócios Jurídicos, RT, São Paulo, 1989. Mota Pinto, Carlos Alberto - Contrato de Adesão, in Revista Forense, vol. 73, p.33-43, jan./mar., 1977.

Nery, Nelson Júnior - $\mathrm{Da}$ Proteção Contratual, in Código Brasileiro de Defesa do Consumidor (Comentado pe los autores do anteprojeto), Fundação Universitária, 1991 Oliveira, Fernando Albino. Fundo de Comércio em Shopping Centers, in Shopping Centers - Questões Juríd cas, Saraiva, São Paulo, 1991.

Rieg, Alfred - Le Rôle de la volonté dans la Formation de

l'Acte Juridique d'aprés les doctrines allmenades du XIX siècle, in Archives de Philosophie du Droit, 26/126, $\mathrm{Pa}$ ris, 1987

Roppo, Enzo - O Contrato, Trad. Ana Coimbra Januário Gomes. Almedina, Coimbra, 1988. Salleiles, Raymond - De la Déclaration de Volonté, F. Pichon, Succeseur Editeur, Paris, 1901.

Santos, Cláudio. A Locação de Espaço em Shopping Centers, in RT 680, p.19.

Schwab, Dieter - Liberdade Contratual e Formação dos Contratos ex vi legis, in Rev. Ajuris, 39/16.

Stiglitz, Gabriel - Proteccion Jurídica del Consumidor, Depalma, Buenos Aires, 1990.

Stolfi, Giuseppe - Teoria del Negocio Juridico, Ed. Rev. de Derecho Privado, Madrid, 1959.

Villey, Michel - Essor et D'cadence du Voluntarisme Villey, Michel - Essor et Décadence du Voluntarisme Wique, in Archives de Philosophie du Droit, $\mathrm{n}^{\circ} 4,1957$. Trad. Jose Luis Carro, Civitas, Madrid, 1982

\title{
Defesa de direitos coletivos e defesa coletiva de direitos
}

\section{Teori Albino Zavascki}

Juiz do TRF - $4^{a}$ Região. Professor de Processo Civil da UFRGS.

\section{SUMÁRIO}

I - Introdução; II - Direitos difusos e coletivos e direitos individuais homogêneos: distinções; III - Instrumentos de defesa de direitos coletivos. Ação Civil Pública - características gerais. Ação Popular - características gerais; IV Instrumentos de defesa coletiva de direitos individuais (homogêneos). Substituição processual e representação. Instrumento tradicional - o litisconsórcio ativo por representação. Novos instrumentos, por substituição processual; IV. 1. - Mandado de Seguranca Coletivo. Finalidade - correntes de opinião. Finalidade - defesa de direitos subjetivos individuais. Procedimento. Objeto de impetração e interesse jurídico. Impetrac̃o por Partidos Políticos. Partidos Políticos - limitações quanto ao objeto. Rol dos legitimados - possibilidade de ampliação. Autonomia do impetrante

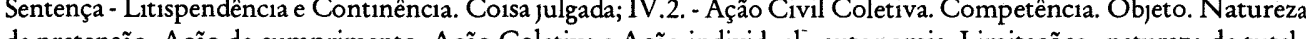
da pretensão. Ação de cumprimento. Ação Coletiva e Ação individual - autonomia. Limitaçôes - natureza da tutela e providêcia cautelares. lispendencia. Coisa julgada; $V$ - Defesa coletiva de diretos individuais pelo ministério público. Hipóteses autorizadas em Lei Constitucionalidade da legitimação. Hipótese não expressamente autorizada em Lei. Limites da atuação - interesses sociais. VI - Conclusões.

\section{Abstract}

The concept of collective interests (those that pertain to a class of individuals, but to no one in particular) cannot be extended to individual rights apt to be claimed in aggregated form. Each of these categories are singled out not only by their essential nature, but also by their procedural treatment.

\section{I - Introdução}

1. Os últimos anos marcaram no Brasil um período de importantes inovações legislativas a respeito dos chamados "direitos e interesses difusos e coletivos" e dos mecanismos de tutela coletiva de direitos, destacando-se: a Lei ${ }^{\circ}$ 7.347, de 24.07.85 (disciplinando a chamada "ação civil pública"), a Constituição de 1988 (alargando o âmbito da ação popular, criando o mandado de segurança coletivo e a legitimação do Ministério Público para promover ação civil pública e privilegiando a defesa do consumidor) e, finalmente, o Código de Proteção e Defesa do Consumidor (Lei no 8.078, de 11.09.90, que, entre outras novida- des, introduziu mecanismo de defesa coletiva para "direitos individuais homogêneos"). A entusiástica utilização, que se seguiu, dos novos mecanismos processuais, nem sempre se deu de modo apropriado, às vezes por inexperiência de seus operadores - o que é compreensível outras vezes por se imaginar, equivocadamente, que enfim se tinha em mãos o remédio para todos os males: para destravar a máquina judiciária e para salvar a sociedade de todas as agressões do Governo e dos poderosos em geral. $\hat{\mathrm{E}}$ muito salutar, por isso, o processo de revisão crítica que se vem sentindo nos últimos tempos ${ }^{1}$ no sentido de coibir exageros e assim não só preservar do descrédito, mas valorizar e aperfeiçoar esses importantes avanços no campo processual. É com esse mesmo propósito que se buscará aqui reflexão sobre tema que a experiência diária evidencia ser foco de boa parcela dos equívocos: a distinção entre os mecanismos processuais para defesa de direitos coletivos e os mecanismos para defesa coletiva de direitos.

2. Com efeito, o Código de Proteção e Defesa do Consumidor introduziu mecanismo 
especial para defesa coletiva dos chamados "direitos individuais homogêneos", categoria de direitos não raro confundida com os direitos coletivos e difusos e por isso mesmo lançada com eles em vala comum, como se lhes fossem comuns e idênticos os instrumentos processuais de defesa em juízo. Porém, é preciso que não șe confunda defesa de direitos coletivos (e difusos) com defesa coletiva de direitos (individuais). Direito coletivo é direito transindividual (=sem titular determinado) e indivisível. Pode ser difuso ou coletivo "stricto sensu". Já os direitos individuais homogêneos são, na verdade, simplesmente direitos subjetivos individuais. A qualificação de homogêneos não desvirtua essa sua natureza, mas simplesmente os relaciona a outros direitos individuais assemelhados, permitindo a defesa coletiva de todos eles. "Coletivo", na expressão "direito coletivo" é qualificativo de "direito" e por certo nada tem a ver com os meios de tutela. Já quando se fala em "defesa coletiva" o que se está qualificando é o modo de tutelar o direito, o instrumento de sua defesa. Identificar os instrumentos próprios para defesa de cada uma dessas categorias de direitos e estabe-

\begin{tabular}{|c|c|c|c|}
\hline DIREITOS & DIFUSOS & COLETIVOS & $\begin{array}{l}\text { INDIVIDUAIS } \\
\text { HOMOGÊNEOS }\end{array}$ \\
\hline $\begin{array}{l}\text { 1) Sob o aspecto subjetivo } \\
\text { são: }\end{array}$ & \begin{tabular}{|l|} 
Transindividuais, com \\
determinação absoluta dos \\
titulares (= não têm titular \\
individual e a ligação entre \\
os vários titulares difusos \\
decorre de mera circuns- \\
tância de fato. No exemplo: \\
morar na mesma região.)
\end{tabular} & $\begin{array}{l}\text { Transindividuais, com de- } \\
\text { terminação relativa dos ti- } \\
\text { tulares (= não têm titular } \\
\text { individual e a ligação entre } \\
\text { os vários titulares coletivos } \\
\text { decorre de uma relação ju- } \\
\text { rídica-base. No exemplo: O } \\
\text { Estatuto da OAB. }\end{array}$ & $\begin{array}{l}\text { Individuais: (= há perfeita } \\
\text { identificação do sujeito, as- } \\
\text { sim da relação dele com o } \\
\text { objeto do seu direito). A } \\
\text { ligação que existe com ou- } \\
\text { tros sujeitos decorre da cir- } \\
\text { cunstância de serem titula- } \\
\text { res (individuais) de direitos } \\
\text { com "origem comum". }\end{array}$ \\
\hline $\begin{array}{l}\text { 2) Sob o aspecto objetivo } \\
\text { são: }\end{array}$ & \begin{tabular}{|l|} 
Indivisíveis (= não podem \\
ser satisfeitos nem lesados \\
senão em forma que afete a \\
todos os possíveis titulares).
\end{tabular} & $\begin{array}{l}\text { Indivisíveis (= não podem } \\
\text { ser satisfeitos nem lesados } \\
\text { senão em forma que afere a } \\
\text { todos os possíveis titulares). }\end{array}$ & $\begin{array}{l}\text { Divisiveis (= podem ser sa- } \\
\text { tisfeitos ou lesados em for- } \\
\text { ma diferenciada e indivi- } \\
\text { dualizada, satisfazendo ou } \\
\text { lesando um ou alguns titu- } \\
\text { lares sem afetar os demais). }\end{array}$ \\
\hline 3) Exemplo & $\begin{array}{l}\text { Direito ao meio ambiente } \\
\text { sadio (CF, art. 225). }\end{array}$ & $\begin{array}{l}\text { Direito de classe dos advo- } \\
\text { gados de ter representante } \\
\text { na composição dos Tribu- } \\
\text { nais (CF, 107, I). }\end{array}$ & $\begin{array}{l}\text { Direito dos adquirentes a } \\
\text { abatimento proporcional } \\
\text { do preşo pago na aquisição } \\
\text { de mercadoria viciada } \\
\text { (Cód. Consumidor, art. } \\
\left.18, \mathbb{1} 1^{2}, \mathrm{III}\right) \text {. }\end{array}$ \\
\hline
\end{tabular}

\begin{tabular}{|c|c|c|c|}
\hline \multirow[t]{5}{*}{\begin{tabular}{l|l}
$\mathrm{n}$ decorrência de sua \\
reza
\end{tabular}} & $\begin{array}{l}\text { a) - são insuscetíveis de } \\
\text { aproppriação individual }\end{array}$ & \begin{tabular}{|l|} 
a) - são insuscetíveis de \\
apropriação individual
\end{tabular} & $\begin{array}{l}\text { a) - individuais e divisíveis, } \\
\text { fazem parte do patrimônio } \\
\text { individual do seu titular. } \\
\end{array}$ \\
\hline & $\begin{array}{l}\text { b) - são insuscetiveis de } \\
\text { transmissão, seja por ato } \\
\text { "inter vivos", seja "mortis } \\
\text { causa" }\end{array}$ & $\begin{array}{l}\text { b) - são insuscetíveis de } \\
\text { transmissão, seja por ato } \\
\text { "inter vivos", seja "mortis } \\
\text { causa" }\end{array}$ & $\begin{array}{l}\text { b) - são transmissiviveis por } \\
\text { ato “inter vivos" (cessão) } \\
\text { ou "mortis causa", salvo } \\
\text { exceçôes (direitos extrapa- } \\
\text { trimoniais) }\end{array}$ \\
\hline & $\begin{array}{l}\text { c) - são insuscetíveis de re- } \\
\text { núncia ou de transação }\end{array}$ & $\begin{array}{l}\text { c) - são insuscetíveis de re- } \\
\text { núncia ou de transaçãao }\end{array}$ & $\begin{array}{l}\text { c) - são suscetíveis de re- } \\
\text { núncia e transação, salvo } \\
\text { exceções (v.g. direitos per- } \\
\text { sonalíssimos). }\end{array}$ \\
\hline & \begin{tabular}{|l|} 
d). - sua defesa em júzo se \\
dá sempre em forma de \\
substituição processual (o \\
sujeito ativo da relação \\
processual não é o sujeito \\
ativo da relação de direito \\
material), razão pela qual o \\
objeto do litígio é indispo- \\
nível para o autor da de- \\
manda, que não poderá ce- \\
lebrar acordos, nem renun- \\
ciar, nem confessar. (CPC, \\
351) nem assumir ônus \\
probatório não fixado na \\
Lei (CPC, 333, parágrafo \\
único, I) \\
\end{tabular} & \begin{tabular}{|l|} 
d) - sua defesa em jú́zo se \\
dá sempre em forma de \\
substituição processual (o \\
sujeito ativo da relação \\
processual não é o sujeito \\
ativo da relação de direito \\
material), razão pela qual o \\
objeto do litígio é indispo- \\
nível para o autor da de- \\
manda, que não poderá ce- \\
lebrar acordos, nem renun- \\
ciar, nem confessar (CPC, \\
351) nem assumir ônus \\
probatório não fixado na \\
Lei (CPC 333, parágrafo \\
único, I)
\end{tabular} & $\begin{array}{l}\text { d) - são defendidos em juí- } \\
\text { zo, geralmente, por seu } \\
\text { próprio titular. A defesa } \\
\text { por terceiro o será em for- } \\
\text { ma de representação (com } \\
\text { aquiescência do titular). O } \\
\text { regime de substituição } \\
\text { processual dependerá de } \\
\text { expressa autorização em } \\
\text { Lei (CPC, art. } 6^{\circ} \text { ) }\end{array}$ \\
\hline & $\begin{array}{l}\text { e) - a mutação dos titulares } \\
\text { ativos difusos da relação de } \\
\text { direito se dá com absoluta } \\
\text { informalidade jurídica (bas- } \\
\text { ta alteração nas circunstân- } \\
\text { cia de fato). }\end{array}$ & $\begin{array}{l}\text { e) - mutação dos titulares } \\
\text { coletivos da relação jurídi- } \\
\text { ca de direitos material se dáá } \\
\text { com relativa informalidade } \\
\text { (basta a adesão ou a exclu- } \\
\text { são do sujeito à relação ju- } \\
\text { rídica-base). }\end{array}$ & $\begin{array}{l}\text { e) - a mutação do pólo } \\
\text { ativo na relação de direito } \\
\text { material, quando admitida, } \\
\text { ocorre mediante ato ou fa- } \\
\text { to jurídico típico e especí- } \\
\text { fico (contrato, sucessão } \\
\text { "mortis causa", usucapião, } \\
\text { etc). }\end{array}$ \\
\hline
\end{tabular}

4. Embora, como se viu, apresentem entre gumas diferenças - que na prática nem semsão visíveis com clareza - os direitos difusos ; direitos coletivos, ambos transindividuais, ıdivisíveis, são espécies do gênero direitos etivo, denominação também adotada para ntificá-los em conjunto. No entanto, direiindividuais, conquanto homogêneos, são eitos individuais e não transindividuais. Peca $r$ substancial e insuperável antinomia afirrr-se possível a existência de direitos indiviais transindividuais!

\section{III - Instrumentos de defesa de} direitos coletivos

Ação Civil Pública - características gerais: 5. Dentre os instrumentos processuais típicos de defesa de direitos transindividuais e indivisíveis merece destaque a conhecida "ação civil pública”. Criada pela Lei n ${ }^{\circ} 7.347$, de 1985 , e composta de um conjunto de mecanismos destinados a instrumentar demandas preventivas, cominatórias, reparatórias e cautelares de quaisquer direitos e interesses difusos e coleti- 
vos, foi seguida pela Lei $\mathrm{n}^{\circ} 7.853$, de 24.10.89, que nos artigos $3^{\circ}$ a $7^{\circ}$ disciplina especificamente a tutela dos direitos e interesses coletivos e difusos das pessoas portadoras de deficiência, pela Lei ${ }^{\circ} 8.069$, de 13.07 .90 , que em seus artigos 208 a 224 disciplina especificamente a tutela dos direitos e interesses coletivos $\mathrm{e}$ difusos das crianças e adolescentes, e pela Lei $\mathrm{n}^{\circ} 8.078$, de 11.09 .90 , cujos artigos 81 a 104 (salvo a parte especificamente relacionada com direitos individuais homogêneos, arts. 91 a 100) disciplinam a tutela dos direitos e interesses difusos e coletivos dos consumidores. Mesmo com essa complementação, manteve-se, na essência, a linha procedimental adotada pela Lei $\mathrm{n}^{\circ} 7.347$, de 1985 - cuja invocação subsidiária é feita pelas demais Leis citadas - e sob esse aspecto cabe-lhe a denominação comum de ação civil pública, aqui adotada para diferenciála da ação civil coletiva, adiante referida. Trata-se de mecanismo moldado à natureza dos direitos $e$ interesses a que se destina tutelar - difusos e coletivos. É o que se pode verificar ao simples exame de suas características gerais, semelhantes nas várias Leis mencionadas. Assim, legitimam-se ativamente o Ministério Público, pessoas jurídicas de direito público interno e entidades e associações que tenham entre suas finalidades institucionais a proteção do direito ou interesse a ser demandado em juízo. A ação poderá objetivar qualquer espécie de tutela inclusive a condenatória de obrigação de pagar, de fazer e de não fazer. Havendo condenação em dinheiro, este reverterá a um Fundo gerido por um Conselho, com a participação do Ministério Público, e será utilizado para recompor as lesões causadas. Em se tratando de obrigações de fazer ou não fazer, a condenação poderá ser pela prestação específica ou por outra providência que assegure resultado equivalente ao adimplemento, ou ainda, na impossibilidade dessas soluções, por conversão em perdas e danos. A sentença fará coisa julgada erga omnes, salvo em caso de improcedência por insuficiência de provas, em se tratando de direitos ou interesses difusos, e fará coisa julgada ultra partes, mas limitada ao grupo, categoria ou classe titular do direito ou interesse, quan do coletivo, salvo, aqui também, em caso de improcedência por insuficiência de provas. A legitimação dos substitutos processuais prolonga-se inclusive para a ação de execução em favor do Fundo, já que, é bom salientar, são indeterminados os credores da obrigação.

\section{Ação Popular - características gerais:}

6. Outro instrumento de defesa de interesses difusos e coletivos é a ação popular de que trata a Lei $\mathrm{n}^{\circ} 4.717$, de 1965 . Com a configuração que lhe deu a Constituição Federal de 1988, esta ação visa a "anular ato lesivo ao patrimônio público ou de entidade de que o Estado participe, à moralidade administrativa ao meio ambiente e ao patrimônio histórico e cultural" (art. $5^{\circ}$, LXXIII). Legitima-se como demandante o cidadão, ou seja, pessoa física que esteja no gozo dos seus direitos políticos. Admite-se não apenas pretensão anulatória do ato lesivo, mas igualmente a de tutela preventiva, tendente a impedir sua prática e ainda, se for o caso, a de tutela cautelar para suspenderlhe a execução. A coisa julgada tem eficácia erga omnes, salvo em caso de improcedência por insuficiência de provas. $O$ autor da ação popular legitima-se como tal porque, ainda quando esteja imediatamente demandando.proteção a direito titularizado em nome de determinada pessoa jurídica, está, na verdade, defendendo mediatamente interesses da sociedade, a quem pertencem, em última análise, os bens tutelados. É por isso que se afirma que também a ação popular, sob este aspecto, constitui ins trumento de defesa de interesses coletivos, e não individuais.

7. Reitera-se, portanto: não se pode confundir defesa de direitos coletivos com defesa coletiva de direitos individuais. Os instrumentos até aqui referidos, pela destinação expressa que lhes deu o legislador e pelas próprias características com que foram concebidos, são talhados para defesa de direitos coletivos, e não defender coletivamente direitos subjetiindividuais, que têm, para isso, seus pró$s$ mecanismos processuais, como se passaver.

V - Instrumentos de defesa coletiva de direitos individuais (homogêneos)

Substituição processual e representação: 8. Direitos individuais homogêneos são, 1o já se disse, simplesmente direitos subjes individuais, divisíveis e integrados ao imônio de titulares certos, que sobre ele rcem, com exclusividade, o poder de disição.

Nessas circunstâncias, e ao contrário do que rre com os direitos coletivos e difusos (que não terem titular determinado são defenos, necessariamente, por substitutos procesis), os direitos individuais, em regra, só pon ser demandados em juízo pelos seus próos titulares. O regime de substituição prosual aqui é exceção e, como toda exceção, rece interpretação restrita, podendo ser incado somente nas hipóteses e nos limites que ei autorizar (CPC, art. $\left.6^{\circ}\right)$. O caráter excional da substituição processual resulta ramente evidenciado no art. $5^{\circ}$, inc. XXI, Constituição que, ao atribuir às entidades ociativas em geral legitimidade para atuar juízo.em defesa de seus filiados, ndicionou tal atuação à autorização especía do associado, submetendo-a, assim, a regie de representação. Desse dispositivo resulta infirmada a regra segundo a qual a defesa jucial de direitos individuais depende sempre autorização, ou do titular do direito, ou da pressa disposição da Lei. Mais do que um eceito, é um princípio: em se tratando de reitos individuais, ainda que homogêneos ou lacionados com interesses associativos, o re me de representação é a regra, e o da substiiç̧ão processual é a exceção e como tal deve in interpretado.
Instrumento tradicional - o litisconsórcio ativo por representação:

9. Por serem homogêneos, isto é, por terem origem comum e assim se assemelharem outros direitos individuais, prestam-se certos direitos subjetivos à demanda conjunta. Há um modo tradicional de defesa coletiva de direitos individuais: é o litisconsórcio ativo facultativo. Realmente, direitos com origem comum são sem dúvida direitos afins por ponto comum de fato ou de direito, tal como prevê o art 46, IV, do CPC. A defesa coletiva em litisconsórcio será viável, portanto, mediante legitimação ordinária e sem outra restrição que não a da eventual recusa, como pode ocorrer, por exemplo, quando, pelo grande número de demandantes, haja dificuldade de exercício da defesa.

\section{Novos instrumentos, por substituição}

processual:

10. Há, contudo, outros mecanismos de defesa coletiva de direitos subjetivos individuais, que o legislador brasileiro houve por bem introduzir em nosso sistema com o objetivo de tornar mais simples, mais rápida, mais efetiva e mais acessível a prestação jurisdicional, o que há não pode ser alcançado adequadamente apenas pelas vias tradicionais. Dois são eles, essencialmente: o mandado de segurança coletivo, previsto no art. $5^{\circ}, \mathrm{LXX}$, da Constitujção, e a Ação Civil Coletiva, prevista nos artigos 91 a 100 do Código de Proteção e Defesa do Consumidor (Lei n ${ }^{\circ} 8.078$, de 1990). A técnica utilizada pelo legislador e que constitui a marca registrada comum aos dois instrumentos diz com a legitimação ativa, que é em regime de substituição processual autônoma: o autor da demanda, substituto, defende em juízo, em nome próprio, direito de outrem, o que faz autonomamente, isto é, independentemente do consentimento ou mesmo da ciência do substituído. 


\section{1 - Mandado de segurança coletivo}

Finalidade - correntes de opinião:

11. Do mandado de segurança coletivo há quem pense tratar-se de instrumento para salvaguardar unicamente direitos coletivos ${ }^{2}$ e assim chegou a decidir o Superior Tribunal de Justiça ${ }^{3}$. Há, por outro lado, quem sustente poder ele ser utilizado tanto em defesa de direitos coletivos, quanto de direitos individuais ${ }^{4}$. E, finalmente, em terceira orientação, estão os que pensam tratar-se, simplesmente, de instrumento para defesa coletiva de direitos subjetivos individuais ${ }^{5}$. Esse entendimento mereceu o aval importantíssimo do Supremo Tribunal Federal 6 .

Finalidade - defesa de direitos subjetivos individuais:

12. Em verdade, para proteção de direitos coletivos ou mesmo difusos, desde que líquidos e certos, contra ato ou omissão de autoridade, não se fazia necessário modificar o perfi constitucional tradicional do mandado de segurança. Muito antes da Constituição de 1988 , que criou o mandado de segurança coletivo, a jurisprudência já admitia, por exemplo, que Sindicatos ou a Ordem dos Advogados do Brasil, impetrassem mandado de segurança - indi vidual - para defender interesses gerais de classe, vale dizer, típicos direitos coletivos, pois que transindividuais, indivisíveis, pertencentes a um grupo indeterminado de pessoas ${ }^{7}$. Tudo é apenas uma questão de legitimação: configurada lesão a direito difuso ou coletivo líquido e certo - e esta configuração certamente não é corriqueira - não haverá empecilho algum ao acesso dos legitimados à via mandamental tradicional. Aliás, essa via de tutela de direitos coletivos está implicitamente admitida pelo Código do Consumidor (art. 83) e de modo explícito pelo Estatuto da Criança e do Adolescente (art. $212, \$ 2^{\circ}$ ). Assim, a única novidade introduzida pelo constituinte de 1988 foi a de autorizar que o mandado de segurança possa ser utilizado por certas entidades para, na condição de substitu- tas processuais, buscarem tutela de um conjun to de direitos subjetivos de terceiros. O que há de novo, destarte, é apenas uma forma de defesa coletiva de direitos individuais, e não uma forma de defesa de direitos coletivos. Se o propósito, no mandado de segurança coletivo, tivesse sido o de viabilizar a tutela de direitos coletivos, não se poderia compreender que entre os legitimados a utilizá-lo não estivesse o Ministério Público, a quem a Constituição atribuiu, como função institucional, a defesa dessa categoria de direitos (CF, art. 129, III). Sua exclusão, na verdade, evidencia mais uma vez que o mandado de segurança coletivo é instrumento de defesa de direitos individuais, defesa que, em princípio, é incompatível com as atribuições constitucionais do Ministério Público (CF, art. 127).

\section{Procedimento}

13. A legitimação ativa dos Partidos Políticos, organizações sindicais, entidades de classe e associações, para impetrar mandado de segurança coletivo é extraordinária, já que, na condição de substitutos processuais, demandam em nome próprio direito alheio. Quanto ao regime procedimental, inclusive no que diz com o prazo para impetração, a liminar e os recursos, o mandado de segurança coletivo se submete às disposições normativas gerais do mandado de segurança. A competência do juízo há de ser fixada em consideração à autoridade coatora, que, por sua vez, só poderá ser a que ostentar, entre suas atribuições, em plexo de poderes e competências que a habilitem, em caso de procedência, a atender a pretensão deduzida e em relação a todos os substituídos. Quanto a estes aspectos, como se vê, o mandado de segurança coletivo não é diferente do mandado de segurança plúrimo, isto é, o impetrado em litisconsórcio ativo, por representante credenciado pelos titulares do direito individual (que, aliás, não deixa de ser uma forma de defesa coletiva de direitos).
Objeto da impetração e interesse jurídico:

14. No que se refere ao objeto, a impetração etiva busca tutelar direitos subjetivos indiluais, os quais, para êxito da demanda, den ser líquidos e certos e estar ameaçados ou lados por ato ou omissão ilegítima de autoade. Não, porém, qualquer direito, mas tãomente aquele que guardar relação de tinência e compatibilidade com a razão de

(finalidades, programas, objetivo titucional) da pessoa jurídica impetrante. r quê? Porque para ajuizar qualquer demannão basta que o autor detenha legitimidade. indispensável que tenha também interesse, : 0 artigo $3^{\circ}$ do CPC. Isso se aplica igualnte ao substituto processual, que há de osItar interesse próprio, distinto e cumulado m o do substituído. Ora, esse interesse próo, no caso de mandado de segurança coleti, manifesta-se exatamente pela relação de rtinência e compatibilidade entre a razão de - do substituto e o conteúdo do direito subivo do substituído, objeto da demanda ${ }^{8}$. Não ia concebível que o Partido Político ou qualer dos demais legitimados fossem a juízo para ter-se em defesa de direitos que nem direta $\mathrm{m}$ indiretamente lhes dissessem respeito al$\mathrm{m}$. Sem elo de referência entre o direito afirıdo e a razão de ser de quem o afirma, faltaà ação uma das suas condições essenciais, is o sistema jurídico não comporta hipótese demandas de mero diletantismo, e isso se lica também ao substituto processual.

Impetração por Partidos Políticos:

15. Dispõe a letra "b" do inciso LXX do $\therefore 5^{\circ} \mathrm{da}$ Constituição que o mandado de serança impetrado por organização sindical, tidade de classe ou associação será proposto $m$ defesa de interesses de seus membros ou ;ociados". Entretanto, a letra "a" do mesmo ciso, que prevê a legitimação dos Partidos líticos com representação no Congresso acional, não contém aquela limitação. Há lem sustente que, mesmo assim, a restrição é aplicável aos Partidos Políticos, que somente poderiam demandar tutela para direitos individuais dos seus filiados. Essa é a orientação que predomina na jurisprudência do Superior Tribunal de Justiça 9 . Dois argumentos, pelo menos, militam fortemente em outro sentido. Primeiro, a inexistência da limitação no texto constitucional, o que é especialmente significativo ante a menção expressa a ela no inciso seguinte do mesmo dispositivo, a evidenciar que a omissão anterior não foi desatenta e, portanto, deve merecer interpretação que lhe dê eficácia. Segundo, pela singular natureza do Partido Político, substancialmente diversa das demais entidades legitimadas. Com efeito, as associações - sindicais, classistas e outras - têm como razão existencial o atendimento de interesses ou de necessidades de seus associados. Seu foco de atenção está, portanto, voltado diretamente para seus associados, que, por sua vez, a ela confluíram justamente para receber $a$ atenção e $o$ atendimento de necessidade ou de interesse próprio e particular. É natural, portanto, e apropriado à natureza dessas entidades, que, ao legitimá-las para impetrar segurança, o constituinte tenha estabelecido como objeto da demanda a defesa dos interesses dos próprios associados, limitação inteiramente compatível com o móvel associativo. O que ocorre nos Partidos Políticos, entretanto, é um fenômeno associativo completamente diferente. Os Partidos Políticos não têm como razão de ser a satisfação de interesses ou necessidades particulares de seus filiados, nem são eles o objeto das atividades partidárias. Ao contrário das demais associações, cujo objeto está voltado para dentro de si mesmas, já que ligado diretamente aos interesses dos associados, os Partidos Políticos visam a objetivos externos, só remotamente relacionados a interesses específicos de seus filiados. Segundo estabelece sua Lei Orgânica (Lei no 5.682, de 1971, art. $2^{\circ}$ ) "os partidos políticos ... destinam-se a assegurar, no interesse do regime democrático, a autenticidade do sistema representativo e a defender os direitos fundamentais, definidos na Consti- 
tuição". Por conseguinte, os filiados ao Partido são, na verdade, instrumentos das atividades e das bandeiras partidárias, e não o objeto delas. $O$ objeto das atenções partidárias são os membros da coletividade em que atuam, independentemente da condição de filiados. É bem compreensível, pois, e bem adequada à natureza dos Partidos, a sua legitimação para impetrar segurança coletiva, mesmo em defesa de direitos de não-filiados.

\section{Partidos Políticos - limitações quanto ao} objeto:

16. No que respeita à legitimação dos Partidos Políticos, em suma, o objeto da pretensão do mandado de segurança coletivo tem limites apenas quanto ao seu conteúdo, que há de ser necessariamente apropriado e compatível com a natureza do Impetrante, o que, como antes se disse, é imposição relacionada com o interesse de agir. Mas, quanto à extensão subjetiva dos substituídos, esta não pode ficar limitada aos interesses particulares de seu filiados, pois que tal limitação implicaria não apenas o desvirtuamento da natureza da agremiação - que não foi criada para satisfaze interesses dos filiados - como também a eliminação, na prática, da faculdade de impetrar segurança coletiva.

\section{Rol dos legitimados - possibilidade de} ampliação:

17. O rol dos legitimados a impetrar segurança coletiva, elencado na Constituição entre os direitos e garantias fundamentais, constitui, como tal, um núcleo mínimo de legitimação que, se não pode ser reduzido nem limitado pelo legislador ordinário, nada impede que seja por esse ampliado. Tratando-se, como se trata, de matéria relacionada com legitimação processual, nenhum empecilho existia antes de 1988, como não existe agora, à criação, por norma infra-constitucional, de hipóteses novas de legitimados a impetrar mandado de segurança em nome próprio em defesa de direito de outrem.
Autonomia do impetrante:

18. Exatamente em razão do interesse jurídico antes referido ( = relação de pertinência e de compatibilidade entre o direito material afirmado em juízo, titularizado na pessoa dos associados ou filiados, e os fins institucionais do impetrante), o ajuizamento da ação dispensará qualquer espécie de autorização individual ou de assembléia. $\mathrm{Na}$ petição inicial não se fará necessário nem mesmo identificar particularmente cada um dos titulares do direito material. Ao impetrante, substituto processual, incumbirá, no entanto, fixar exatamente o âmbito de sua representatividade e os seus objetivos existenciais, elementos esses indispensáveis para demonstrar o interesse processual, para estabelecer os limites da legitimação e para identificar (a) os substituídos atingidos pela sentença, (b) a autoridade impetrada e (c) o juízo competente. Enfatizo um ponto: o critério geográfico do domicílio dos substituídos é elemento neutro para os efeitos apontados. Os substituídos atingidos pela eficácia da sentença serão os abrangidos no âmbito da representatividade do impetrante, independentemente do seu domicílio. A situação fática do domicílio, que por si só não inibe nem limita a formação de litisconsórcio ativo em mandado de segurança, é, por idêntica razão, irrelevante para a impetração coletiva, que daquele se diferencia, a rigor, apenas pela legitimação em regime de substituição processual. O que importa, frisese, é delimitar o âmbito da representatividade do impetrante, este sim elemento importante para as demais definições (da autoridade coatora, do juízo competente, etc.).

\section{Sentença:}

19. A sentença no mandado de segurança coletivo será substancialmente idêntica à de qualquer mandado de segurança, tirante, é certo, o grau de generalidade próprio de uma demanda coletiva em que a inicial não identificou particularmente nem o nome nem a situação de cada um dos titulares do direito afirmado. Tal especificação, se necessária, será proce- ida quando do cumprimento do julgado, portunidade em que serão decididas eventuis controvérsias relacionadas com a condição special dos substituídos.

\section{Litispendência e continência:}

20. Entre o mandado de segurança coletio e o mandado de segurança proposto indiviualmente com o mesmo objeto e a mesma ausa haverá uma relação de continência e coneúdo, a determinar: a) a extinção por itispendência do processo de mandado de seurança individual superveniente ao coletivo $\mathrm{u}, \mathrm{b})$ a reunião de ambos, por continência, ierante o juízo do mandado de segurança coetivo, quando este for ajuizado em segundo ugar. Justifica-se a competếncia do juízo coleivo em tal hipótese - em contrário à regra dos rtigos 106 e 219 do CPC - especialmente em ace à pluralidade de demandas individuais peante juízes diversos.

\section{Coisa julgada:}

21. Mesmo ajuizado por substituto procesual, o mandado de seguranca coletivo terá senença com eficácia de coisa julgada material para odos os substituídos, desde que, evidentemene, nela haja pronunciamento específico sobre , direito afirmado pelo impetrante. Assim, a lenegação da ordem por insuficiência de proras implicará negação de direito líquido e cer0 , mas não a negação do direito propriamene dito. Em hipóteses tais, coisa julgada mate‘ial não haverá, incidindo, em consequiência, egra do art. 15 da Lei ${ }^{\circ} 1.533$, de 1951.

\section{2 - Ação civil coletiva}

22. Outra hipótese de defesa coletiva de lireitos subjetivos individuais é a prevista nos urtigos 91 a 100 do Código de Proteção e Deesa do Consumidor (Lei $n^{\circ} 8.078$, de 11.09.90) כ Título III desse Código, que trata "da defesa to consumidor em juízo", estabelece distinções mportantes entre a configuração processual da lefesa dos direitos coletivos e difusos dos con- sumidores e da defesa dos seus direitos individuais. Para esse último caso, há regras específicas, em capítulo próprio. Os entes legitimados, elencados no art. 82, embora comuns, têm, quando em defesa de direitos individuais, limitações maiores que quando demandam por direitos coletivos e difusos. Em suma, os regimes são diferentes, e suas diferenças merecem a devida consideração do intérprete.

\section{Competência:}

23. A primeira distinção a assinalar diz respeito à competência. Em se tratando de direitos difusos e coletivos, a demanda deverá ser proposta no foro do local onde ocorrer o dano, "cujo juízo terá competência funcional para processar e julgar a causa". É o que dispõe o art. $2^{\circ}$, da Lei $n^{\circ} 7.347$, de 1985. Já se firmou en tendimento jurisprudencial de que essa competência funcional do juízo local comporta inclusive as causas de que participam entes federais, hipótese em que, não havendo vara federal instalada na comarca, competente será o juízo estadual, considerando-se recepcionado pelo art. $109, \$ 3^{\circ}$, parte final, da Constituição o dispositivo acima referido ${ }^{10}$. Esse regime, aplicável em todos os casos de direitos difusos e coletivos, exceto os previstos no Estatuto da Criança e do Adolescente (que tem regra própria no art. 209), não se aplica às demandas coletivas de responsabilidade por danos individuais, sujeitas a regime competencial próprio, o do artigo 93 da Lei $n^{\circ} 8.078$, de 1990, a saber: competente será o juízo do local do dano (ou da Capital do Estado, se os danos forem de âmbito nacional ou regional), "ressalvada a competência da justiça federal". Ou seja, nestas hipóteses, o juízo estadual não está autorizado a exercer em primeiro grau a jurisdição federal, como ocorre na ação civil pública destinada à tutela de direitos coletivos.

\section{Objeto:}

24. A segunda observação importante diz com o objeto da demanda. Em se tratando de direitos coletivos, o legislador estabeleceu 
legitimação extraordinária amplíssima, de tal modo que as entidades legitimadas estão autorizadas a buscar tutela a direitos coletivos relacionados ao consumidor (Lei n ${ }^{\circ} 8.078$, de 1990 art. 81, parágrafo único, I e II) e também ao meio ambiente, aos bens e direitos de valor histórico, artístico, estético, paisagístico e turístico e, enfim, a qualquer outro interessé difuso ou coletivo (Lei $n^{\circ} 7.347$, de 1985, art. $1^{\circ}$ ). Em se tratando de direitos individuais homogêneos, contudo, a legitimação extraordinária é restrita à ação coletiva de responsabilidade por danos individualmente sofridos por consumidores (Lei n ${ }^{\circ} 8.078$, de 1990, art. 81, parágrafo único, III, e art. 91). Assim, ressalvada a legitimação do Ministério Público, de que mais adiante se tratará, nenhum dos entes mencionados no art. 82 da Lei n ${ }^{\circ} 8.078$, de 1990, est habilitado a defender coletivamente direitos individuais, ainda que homogêneos, a não ser na restrita hipótese de danos decorrentes de relações de consumo. Convém repetir que a legitimação para defender em nome próprio direito individual de outrem, em regime de substituição processual, é extraordinária e excepcional, que só a Lei pode conferir (CPC, art. $6^{\circ}$ ) e como tal não está sujeita a interpretações ampliativas.

\section{Natureza da pretensão:}

25 . No que se refere à natureza da pretensão, diz a Lei que a ação coletiva é de responsabilidade por danos individualmente sofridos (art. 91), sendo que "em caso de procedência do pedido, a condenação será genérica, fixando a responsabilidade do réu pelos danos causados". A pretensão, conseqüentemente, há de ter natureza condenatória 11 . Refogem ao âmbito da legitimação extraordinária em causa pretensões de outra natureza, notadamente a constitutiva cuja sentença, com eficácia imediata e concre$\mathrm{ta}$, independentemente de posterior ação de execução, não é compatível com provimentos de natureza genérica. Ademais, conforme adiante se verá, a sentença constitutiva não comportaria a opção, que o sistema criou em favor do titular do direito material, de se submeter ou não à ação coletiva e de executar ou não, em seu favor, a sentença genérica que nela vier a ser proferida. Por outro lado, coerente com essa mesma orientação, e bem significativamente, o legislador estabeleceu que a pretensão declarativa de nulidade a cargo do Ministério Público (excluídos outros legitimados) fica submetida à iniciativa do consumidor ou de seu representante, com o que se descaracteriza o regime de substituição processual autônoma. É o que se depreende do art. 51, $\$ 4^{\circ}$, da Lei em foco, dispositivo, aliás, de duvidosa constitucionalidade, já que atribui ao Ministério Público a defesa particular, em regime de representação, de direitos individuais disponíveis, ao arrepio do art. 127 da Constituição Federal.

\section{Ação de Cumprimento:}

26. Obtida a sentença genérica de procedência, cessa a legitimação extraordinária. A ação específica para seu cumprimento, em que os danos serão liquidados e identificados os respectivos titulares, dependerá da iniciativa do próprio titular do direito lesado, que será, por conseguinte, representado e não substituído no processo. Aliás, mesmo quando ajuizada coletivamente, como prevê o art. $98 \mathrm{da} \mathrm{Lei,} \mathrm{a} \mathrm{ação}$ de cumprimento se desenvolverá em litisconsórcio ativo, em que os titulares do direito serão nomeados individualmente identificadas particularmente as lesões sofridas. Assim, ainda nestes casos, a ação de cumprimento será proposta em regime de representação, e não de substituição processual ${ }^{12}$. Por outro lado, a falta de iniciativa do interessado, no prazo de um ano, importará decadência do direito de cumprir o julgado em seu favor, hipótese em que os resíduos condenatórios - apurados e liquidados em ação proposta por qualquer dos entes relacionados no art. 82, em regime, agora novamente, de substituição processual - reverterão em favor do Fundo criado pela Lei $n^{\circ} 7.347$, de 1985 . É o que estabelece o art. 100, da Lei ${ }^{\circ}$ 8.078, de 1990. Importa alientar que, ao contrário do que se poderia oncluir de uma interpretação puramente liteal daquele dispositivo, a reversão em favor do 'undo certamente não poderá compreender is valores já pagos aos que se habilitaram temrestivamente, nem os devidos aos interessado jue, no prazo legal, tenham promovido a ação le cumprimento, ainda em curso.

\section{Ação Coletiva e Ação Individual -}

\section{autonomia:}

27. O caráter genérico da sentença de pro:edência e a inviabilidade de sua liquidação $e$ xecução por substituto processual autônomo ão dois indicativos importantes da opção fe a pelo legislador brasileiro em tema de defesa :oletiva de direitos individuais, qual seja: o tiular do direito material não pode ser obrigaoriamente vinculado ao processo ou aos efei:os da sentença. Em outras palavras, diferentenente do que se passa no mandado de seguança coletivo, aqui, na ação civil coletiva em exame, o legislador brasileiro privilegiou claramente o direito à liberdade da ação, que tem somo contrapartida necessária a faculdade de não acionar, e até de renunciar, se esta for a vontade do titular do direito. Esta opção se manifesta, também, no art. 94 da Lei (ao estabelecer como faculdade do interessado o seu ingresso como litisconsorte), no art. 103, III (ao estabelecer que a coisa julgada material erga omnes somente se dará em caso de procedência da ação coletiva), e sobretudo no art. 104 segunda parte. Ali se diz que "...os efeitos da coisa julgada erga omnes ou ultra partes a que aludem os incisos II e III do artigo anterior não beneficiarão os autores das ações individuais, se não for requerida sua suspensão no prazo de 30 (trinta) dias, a contar da ciência nos autós da ação coletiva". Desse dispositivo colhe-se (a) que a ação individual pode ter curso independente da ação coletiva superveniente, (b) que a ação individual só se suspende por iniciativa do seu autor $\mathrm{e}(\mathrm{c})$ que não havendo pedido de suspensão, a ação individual não sofre efeito algum do resultado da ação coletiva, ainda que julgada procedente.

\section{Limitações - natureza da tutela e} providências cautelares:

28. A opção clara do legislador, de privilegiar a liberdade do interessado de se vincular ou não aos efeitos da sentença, reforça a conclusão antes enunciada, a saber: a pretensão possível de ser deduzida por substituto processual na ação civil coletiva é apenas a que conduz a uma sentença condenatória genérica, provimento jurisdicional semelhante às decisões normativas do Direito do Trabalho, e que, pelo seu conteúdo, situa-se em posição intermediária entre a absoluta abstração da norma legal e a concretude das sentenças proferidas em demandas individuais. Não é compatível com o sistema, destarte, pretender-se, em regime de substituição processual, sentença coletiva de natureza constitutiva, cuja eficácia atingiria imediata e necessariamente a esfera jurídica dos substituídos, sonegando-lhes a liberdade de optar pela não-vinculação. Essa limitação se estende também às providências cautelares: o substituto processual poderá pleiteá-las, mas desde que se trate de medidas (a) relacionadas com a ação de conhecimento, pois a legitimação extraordinária não existe para a liquidação e execução, já que se esgota com a sentença, e (b) que não importem vinculação necessária do patrimônio jurídico do substituído aos efeitos do provimento jurisdicional.

\section{Litispendência:}

29. Sustentamos, ao tratar do mandado de segurança coletivo, que entre ele e o mandado dè segurança individual opera-se a tríplice identidade, resultando daí, eventualmente, litispendência e coisa julgada. Em se tratando, porém, de ação civil coletiva, a simetria com a ação individual não existe. Com efeito, na ação civil coletiva, a sentença será genérica, e, em caso de procedência, será seguida de outra, a ser proferida na ação de cumprimento, oportunidade em que se individualizará e 
quantificará a sanção condenatória. Já a ação individual traz embutida em si a ação de cum primento, pelo menos em boa parte. Assim entre ação coletiva e ação individual pode haver identidade quanto às partes ( $\mathrm{e}$ sob este aspecto, a coletiva é continente da individual) quanto à causa de pedir. O pedido, porém, é diverso: na coletiva, há simples pedido de condenação genérica, quase que um pedido declaratório; na individual, há pedidos de declaração e de condenação de conteúdo mais específico (aqui há cumulação de ação de cumprimento, lá inexistente). Quanto ao pedido, bem se vê, a ação individual é mais abrangente. Entre as duas, portanto, não há litispendência e tal resulta claro do art. 104 da Lei ${ }^{\circ} 8.078$ de 1990. Há, isto sim, conexão (CPC, art. 103), a determinar o processamento conjunto, perante o juízo da ação coletiva, de todas as ações individuais, anteriores ou supervenientes.

\section{Coisa julgada:}

30. A sentença proferida na ação coletiva terá eficácia de coisa julgada "erga omnes, apenas em caso de procedência do pedido, para beneficiar todas as vítimas e seus sucessores", segundo dispõe o art. 103, III, da Lei. Os limites objetivos da coisa julgada, mesmo neste caso, são os próprios de uma condenação genérica: faz coisa julgada a certificação de que obrigação do réu existe, mas não há coisa julgada - até por não ter sido objeto da demanda - em relação à individualização dos credore e do quanto é devido a cada um, questões que serão dirimidas por outra sentença, na ação de cumprimento. Há, entretanto, duas exceções a regra constante do dispositivo transcrito: a) haverá coisa julgada, mesmo em caso de improcedência, em relação aos que, atendendo ao edital referido no art. 94 , intervierem como litisconsortes, como se depreende do $\mathbb{2} 2^{\circ}$ do artigo 103; e b) não haverá coisa julgada, mesmo em caso de procedência, em relação ao que preferiram manter em curso ações individuais paralelas à ação coletiva, como se depreende do art. 104
V. Defesa coletiva de direitos individuais pelo Ministério Público

Hipóteses autorizadas em Lei:

31. O Ministério Público não está incluído no rol dos entes legitimados a impetrar mandado de segurança coletivo, omissão coerente do legislador constituinte, pois não é próprio daquela instituição atender a interesses particulares. Todavia, o legislador ordinário o habilitou a defender coletivamente direitos individuais não só de consumidores (Lei n ${ }^{\circ} 8.078$, de 1990, arts. 91 e 92), mas também de investidores no mercado de valores mobiliários (Lei $n^{\circ} 7.913$, de 1989) e de credores de instituições financeiras em regime de liquidação extrajudicial (Lei $n^{\circ}$ 6.024, de 1974, art. 46), sejam eles pessoas físicas ou jurídicas, sejam eles necessitados ou não. Será possível compatibilizar a legitimação para defender tais direitos, tipicamente individuais e disponíveis, com a natureza e a finalidade do Ministério Público, instituição destinada à defesa de interesses sociais ou individuais indisponíveis (CF, art. 127) e que está proibida pela Constituição até mesmo de atuar em juízo em nome de entidades públicas (art. 129, IX), quanto mais de pessoas privadas?

Constitucionalidade da legitimação

32. Em estudo específico sobre o tema ${ }^{13}$, respondemos que sim, pelas razões que sucintamente agora reproduzimos. Nas três citadas hipóteses de legitimação, o legislador ordinário estabeleceu uma linha comum e característica: a atuação do Ministério Público objetiva sentença condenatória genérica, mas a liquidação e a execução específica serão promovidas pelo próprio titular do direito individual. $\mathrm{Ou}$ seja: os direitos dos substituídos são defendidos sempre globalmente, impessoalmente, coletivamente. Obtido o provimento jurisdicional genérico, encerra-se a legitimação extraordinária. Por outro lado, nos três casos, a lesão é especialmente significativa, dado que, pela natureza dos bens atingidos e pela dimensão letiva alcançada, houve também lesão a vares de especial relevância social, assim recotecidos pelo próprio constituinte. Com efei, é a Constituição que estabelece que a defedos consumidores é princípio fundamental atividade econômica (art. 170, V), razão pela tal deve ser promovida, inclusive pelo Esta, em forma obrigatória (art. $5^{\circ}, \mathrm{XXXI}$ ). Não trata, obviamente, de proteção individual, ssoal, particular, deste ou daquele consumiir lesado, mas da proteção coletiva dos conmidores, considerados em sua dimensão munitária e impessoal. O mesmo se diga em lação aos poupadores que investem seus rersos no mercado de valores mobiliários ou nto a instituições financeiras. Conquanto suas ssições individuais e particulares possam não $r$ relevância social, o certo é que, quando insideradas em sua projeção coletiva, passam ter relevância ampliada, de resultado maior te a simples soma de posições individuais. $\mathrm{E}$ : interesse social a defesa desses direitos indiduais, não pelo significado particular de cada $\mathrm{n}$, mas pelo que a lesão deles, globalment insiderada, representa em relação ao adequa, funcionamento do sistema financeiro, que segundo a própria Constituição, instrumen fundamental para promover o desenvolviento equilibrado do País e servir os interes$s$ da coletividade (art. 192). Com isso se condi que a legitimação do Ministério Público, ura a defesa de direitos individuais dos consuidores e dos investidores no mercado finaniro, estabelecida nas Leis $\mathrm{n}^{\circ} 6.024$, de 1974 '7.913, de 1989, e no 8.078 , de 1990, é perfeimente compatível com a sua incumbência institucional de defender os interesses sociais, uposta pelo art. $127 \mathrm{da}$ Constituição. Em tois os casos, ressalte-se, a legitimação tem em ira apenas a obtenção de sentença indenatória genérica. A atuação do Ministé ว Público se dá em forma de substituição ocessual e é pautada pelo trato coletivo upessoal dos direitos subjetivos lesados. $\mathrm{E}$ sta dimensão, e somente nela, que a defesa : tais direitos - divisíveis e disponíveis - pode ser promovida pelo Ministério Público sem ofensa à Constituição.

\section{Hipóteses não expressamente}

\section{autorizadas em Lei:}

33. Questão mais delicada é a de saber se o Ministério Público tem legitimação para defender coletivamente outros direitos individuais além daqueles expressamente previstos pelo legislador ordinário. Enfrentando o tema no estudo antes referido, concluímos que não cabe ao Ministério Público bater-se em defesa de direitos ou interesses individuais, ainda que, por terem origem comum, possam ser classificados como homogêneos. Aliás, esta tem sido a orientação do Superior Tribunal de Justiça ${ }^{14}$. Entretanto, em casos excepcionais, devidamente justificados e demonstrados, em que a eventual lesão a um conjunto de direitos individuais possa ser qualificada, à luz dos valores jurídicos estabelecidos, como lesão a interesses relevantes da comunidade, ter-se-ia presente hipótese de lesão a interesse social, para cuja defesa está o Ministério Público legitimado pelo art. 127 da Constituição. Também nestas hipóteses - cuja configuração estará evidentemente sujeita ao crivo do Poder Judiciário - a atuacão do Ministério Público, necessariamente em forma de substituição processual autônoma, limitar-se-á à obtenção dos provimentos genéricos indispensáveis à restauração dos valores sociais comprometidos, sendo-lhe vedado deduzir pretensões que signifiquem, simplesmente, tutela de interesses particulares, ainda que homogêneos, ou de grupo.

Limites da atuação - interesses sociais:

34. Sobre o tema, portanto, é de se asseverar que o art. 127 da Constituição atribui ao Ministério Público a defesa de interesses sociais, assim entendidos aqueles cuja tutela é importante para preservar a organização e o funcionamento da sociedade e para atender suas necessidades de bem-estar e desenvolvimento. Não se podem confundir interesses sociais com interesses de entidades públicas, nem com 0 
conjunto de interesses de pessoas ou de grupos. Direitos individuais só devem ser considerados como de interesse social quando sua lesão tiver alcance mais amplo que o da simples soma das lesões individuais, por comprometer também valores comunitários especialmente privilegiados pelo ordenamento jurídico. A identificação destes interesses sociais compete tanto ao legislador ordinário - como ocor reu nas Leis $\mathrm{n}^{\circ} 8.078$, de $1990, \mathrm{n}^{\circ} 7.913$, de 1989 e no 6.024 , de 1974 - como ao próprio Ministério Público, se for o caso, mediante avaliação de situações concretas não previstas expressamente em Lei. Nesta última hipótese, a identificação do interesse social - cuja existência e relevância hão de ser cumpridamente demonstradas pelo autor - estará sujeita ao indispensável contraditório e ao controle final do Juiz, de modo a que sejam coibidos abusos e desvios de legitimidade.

\section{VI - Conclusões}

35. Em suma: a) direitos coletivos e difusos são transindividuais ("não têm dono certo" como disse Caio Tácito ${ }^{15}$ ) e indivisíveis, não podendo ser satisfeitos ou lesados senão em forma que afete todos os possíveis titulares; $j$ a os direitos individuais, mesmo quando homogêneos em relação a outros, não deixam de ter dono certo, continuam sendo direitos subjetivos individuais; b) o legislador criou mecanismos para defesa de direitos coletivos e difusos (ação civil pública e ação popular), e mecanismos para defesa coletiva de direitos individuais (mandado de segurança coletivo e ação civi coletiva), que pela sua tipicidade e configuração, são inconfundíveis e impróprios para finalidades diversas das que lhes foram destinadas; c) na defesa de direitos coletivos, a substituição processual é a regra, dada a indeterminação dos titulares; na defesa de direitos in dividuais, no entanto, a substituição processual é exceção, e como tal tem interpretação estrita, sendo admissível apenas nos casos e no limites previstos em Lei; d) a técnica adotada pelo legislador para tornar viável a defesa coletiva de direitos individuais, é a da substituição processual autônoma, com características e limites próprios para cada um dos mecanismos processuais criados; e) o mandado de segurança coletivo: - é instrumento de tutela coletiva de direitos subjetivos individuais (e não de direitos coletivos que, se for o caso, poderão ser tutelados pelo mandado de segurança tradicional); - a entidade impetrante deve ostentar interesse jurídico próprio, que se configura pela relação de compatibilidade entre sua natureza e razão de ser, e a natureza dos direitos individuais afirmados em juízo; - as entidades legitimadas, exceto o Partido Político, somente poderão impetrar segurança coletiva como substitutas processuais dos respectivos filiado ou associados; - não é vedado ao legislador ordinário ampliar o rol dos legitimados ativos previsto na Constituição; - a substituição processual é autônoma, dispensada a impetrante de qualquer autorização dos titulares do direito, que serão particularmente identificados por ocasião do cumprimento da sentença; - entre o mandado de segurança coletivo e o individual há relação de continência e conteúdo; - a sentença, quando se pronunciar sobre o próprio direito (e não apenas sobre sua liquidez e certeza) fará coisa julgada em relação a todos os substituídos; f) a ação civil coletiva: - é a prevista no art. 91 da Lei no 8.078, de 1990; - tem regra de competência distinta da ação civil pública; - seu objeto é a tutela de direitos individuais decorrentes de relações de consumo; - a pretensão é de natureza condenatória; - a sentença será genérica e a identificação e individualização dos substituídos e suas específicas situações serão objeto de ação de cumprimento; - não há substituição processual, e sim representação, na ação de cumprimento; o titular do direito material tem a opção de se vincular ou não à ação coletiva e à sentença nela proferida; - extrapolam os limites da substituição processual pretensões de natureza constitutiva (incompatíveis com sentenças genéricas e com a faculdade de não-vinculação
1 substituído), bem assim de providências utelares relacionadas com a ação de cumpriento (sujeita a regime de representação); tre ação coletiva e a individual não há idenlade quanto ao pedido (a ação individua ubute a ação de cumprimento), o que indu nexão, mas não litispendência; - a sentenç procedência fará coisa julgada erga omnes para neficiar, no que se refere ao provimento gerico, todos os possíveis titulares do direito ado, exceto os que, optando pela não aculação, mantiveram demandas individuai ralelas; - a sentença de improcedência fará isa julgada em relação aos que se vincularam ıção coletiva como litisconsortes ativos; $\mathrm{g}$ ) anto ao Ministério Público: - não é da su tureza constitucional defender direitos subivos individuais disponíveis; - nos casos em te o legislador o legitimou para tal (tutela de nsumidores, de credores de instituições finceiras em regime de liquidação, e de in stidores no mercado financeiro), há substiição processual autônoma, para demandar etensão condenatória genérica, em caráte letivo e impessoal; - a compatibilidade consucional dessa legitimação está em que a leว conjunta àqueles direitos individuais im ica também lesão a valores sociais especial ente privilegiados pelo direito positivo, cuja tela é encargo do Ministério Público; - afora casos expressamente previstos em Lei, ,itimação do Ministério Público para defesa direitos individuais poderá ser admitida apes em situações especiais, quando a lesão a njunto dos direitos venha representar, à luz s valores jurídicos estabelecidos, não apenas ioma dos interesses particulares, mas sim o mprometimento de interesses relevantes $\mathrm{d}$ ciedade como um todo.

\section{Notas}

azuo Watanabe, escrevendo sobre "Demandas coletie os problemas Emergentes da Práxis Forense", afiru: "É preciso evitar-se, a todo o custo, que graves er ros, dúvidas e equívocos, principalmente os decorrentes de mentalidade incapaz de captar com sensibilidade social as inovaçóes e os provocados por vedetismo ou espírito político-eleitoreiro, possam comprometer irremediavel-
polisa politico-eleitoreiro, possam comprometer irremediavel-
mente o êxito de todo esse instrumental, que tem tudo mente o exito de todo esse instrumental, que tem tudo
para solucionar adequadamente os inúmeros conflitos de para solucionar adequadamente os inúmeros conflitos de
interesse coletivos que marcam a sociedade contemporấnea. Nos Estados Unidos, onde as class action tem longa tradição, há opiniões favoráveis... e também negativas..., e não são poucos os que manifestam preocupação a respeito de sua correta utilização de modo a não transformálas em instrumento de proveito egoístico de quem as propõe, em vez de fazế-las cumprir objetivos sociais a que se vocacionam. Com maior razão, preocupação redobrada devemos ter no Brasil, onde o individualismo é mais acentuado e não temos ainda tradição no trato com as demandas coletivas" (in "As Garantias do Cidadão na Justiça", das coletivas" (in "As Garantias do Cidadão na Justiça", Teixeira, SP, Saraiva, 1993, pás 186). Rálvio de Figueiredo Teixeira, SP, Saraiva, 1993, pág. 186). Rogerio Lauria Tucci e José Rogério Cruz e Tucci, com a mesma preocupação, dedicaram capítulo especial sobre "Ação Civil Pública e sua Abusiva Utilização pelo Ministério Público” in Devido Processo Legal e Tutela Jurisdicional, SP, RT, 1993. 2 Rodolfo de Camargo Mancuso, "Uma análise Comparativa entre os Objetos e as Legitimações Ativas das Ações Vocacionadas à Tutela dos Interesses Metaindividuais: Mandado de Segurança Coletivo, Ação Civil Pública, Ações do Código de Defesa do Consumidor e Ação Popular", in "Justitia", $\mathrm{n}^{\circ}$ 54, pág. 181, Lúcia Valle Figueiredo, in Perfil do Mandado de Segurança Coletivo, SP, RT, 1989, págs. 15-16.

3 Agravo Regimental no Mandado de Segurança no 266 , Rel. Min. Carlos M. Velloso, Primeira Seção, RSTJ 10/ 254, com a seguinte ementa: "Mandado de Seguranca. Mandado de Seguranç Individual. Mand do Surança. a Co de Seguranca Coletivo. I chancha ca, contra ato de autoridade que cause lesão, IXIX). LXIX). Interesses difusos e coletivos, a seu turno, são protegidos pelo mandado de segurança coletivo (CF, art. $5^{\circ}$, LXX), pela ação popular (CF, art. $\left.5^{\circ}, \mathrm{LXX} I I I\right)$ e pela ação civil pública (Lei $\mathrm{n}^{\circ} 7.347 / 85$ ). II - Agravo Regimental Improvido". Há, entretanto, decisões em outro sentido, admitindo impetração de mandado de segurança coletivo $\mathrm{em}$ em defesa de direitos subjetivos individuais, como v. g., o MS nº 522, Rel. Min. Ilmar Galvão, Primeira Seção, Ementário de Jurisprudência do STJ, $3 / 34$.

4 Ada Pellegrini Grinover, "Mandado de Segurança Coletivo - Legitimação e Objeto", in Revista de Processo, 57, páss. 96-101: Celso Agrícola Barbi "Mandado de Se" . 1990. págs. 67.

J.J. Calmon de Passos, in Mandado de Segurança Coletivo, Mandado de Injunção, Habeas Data - Constituiçãoe 
Processo, Forense, 1989, pág.13; Athos Gusmão Carneiro, "Anotações Sobre o Mandado de Segurança Coletivo”, in AJURIS, 54, págs. 53-74.

6RTJ 142/446-449.

7 RTJ 54/71 e RTJ 89/396

8 A propósito: J.J Calmon de Passos, in op.cit., págs, 12-13. 9 EDcl no MS no 197 , Rel. Min. Garcia Vieira, Primeir Seção, Ementário de Jurisprudência do STJ 4/167-168, em cuja ementa se diz que "A exemplo dos sindicatos e das associações, também os partidos políticos só podem impetrar mandado de segurança coletivo em assuntos integrantes de seus fins sociais em nome de filiados seus, quando devidamente autorizados pela Lei ou por seus quando da jetivos did jetivos de id phos a ele nâ fliados ou interesses difusos e sim direito de natureza politica, como por exemplo os previstos nos artigos 14 a 16 da Constituiçáo Federal No mesmo sentido: ROMS 2423, Rel. Min. Luiz Vicen Cernicchiaro, $6^{\circ}$ Turma, DJ de 22.11.93, pág. 24974. $10 \mathrm{E}$ a orientação predominante no STJ, como se vê, g., do CC n ${ }^{\circ}$ 2.706-0-CE, Rel. Min. Demócrito Reinaldo, Primeira Seção, RSTJ 45/34, em cuja ementa está dito que "A ação civil pública $e$ as demais ações propostas com base na Lei $n^{\circ} 7.347$, de 24 de julho de 1985, devem ser ajuizadas no foro do local onde ocorreu o dano a que se refere seu artigo $2^{\circ}$. Se se trata de comarca em que não há juiz federal, será competente o juiz de direito, cabendo recurso ao Tribunal Regional Federal".No mesmo sentido: $\mathrm{CC} \mathrm{n}^{\circ}$ 2.230-RO, Rel. Min. Pádua Ribeiro, Primeira Seção, DJ de 28.05.93, pág. 10406. 11 Ada Pellegrini Grinover, comentendo o art 95 do Cón Codigo de Proterantor, observou que "A pretensáo processual do autor coletivo, na ação de que trata o presente capítulo, é de natureza condenatoria condenatoria sera a sentença que acolher o pedido". (in Codigo de Proteção e Defesa do Consumidor Comentado Pelos Autores do Anteprojeto, RJ Forense Universitária, $2^{2}$ ed., 1992, pág. 548 )
12 Ada Pellegrini Grinover, nos "Comentários .." citados, referindo-se à legitimação para a liquidação e execução, anotou que”... a liquidação e a execução serão neces sariamente personalizadas e divisíveis. Promovidas que forem pelas vítimas e seus sucessores, estes estarão agindo na qualidade de legitimados ordinários, sendo individua o processo de liquidação e execução. E quando a liquidação e execução forem ajuizadas pelos entes enumerado no art. 82? A situação é diferente da que ocorre com legitimação extraordinária à ação condenatória do art. 91 (...). Lá os legitimados agem no interesse alheio, mas em nome próprio, sendo indeterminados os beneficiários da condenação. Aqui, as pretensões à liquidaç̃o e ex condenaçăo. Aqui, as pretensos à liquidação e execução da sentença serão necessariamente individualizadas: o caso surge como de representação, devendo os entes e pessoa enumerados no art. 82 agirem $u$ sucessores" (op.cit., pág. 553).

13 "O Ministério Público e a Defesa de Direitos Individuais Homogêneos", in Revista de Informação Legislativa a. 30, n.117, pág. 173; Revista Jurídica, v. 41, nº 189, pág. 21.

14 "O interesse de grupos não se confunde com o interesse coletivo. O primeiro, mesmo contando com pluralidade de pessoas o objetivo é comum e limitado, ao passo que no segundo esta afeto a difusão do interesse, alcançando os integrantes da sociedade como um todo". (MS n' 256 DF, Rel. Min. Pedro Acioli, Primeira Seção. DJ de 04.06.90, pág. 5045. Assim: "Ação Civil Pública. Mensalidades escolares. Repasse do aumento dos professores. Ministério Público. Parte llegítima. Não se cuidando de interesses difusos ou coletivos, mas de interesses individuis de um grupo de alunos de um determinato colid. ais de um grupo de alunos de um determinado colégio arasta-se a legitimidade do Minira, RSTJ 54/306).

15 "Controle Jurisdicional da Administração Pública na 15 “Controle Jurisdicional da Administração Pública na
Nova Constituição", in RDP n ${ }^{\circ}$ 91, pág. 30 e ss, 1989, pág. 13;

\section{a Instituição do Pátrio Poder}

\section{rlos Silveira Noronha}

fessor de Teoria Geral do Processo, de Direito Processual Civil e

Direito Civil na Faculdade de Direito da Universidade Federal do Rio Grande do Sul

\section{MÁRIO:}

Conceito e evolução; 2 - Caracteres do pátrio poder; 3 - Os titulares do pátrio poder; 4 - $O$ pátrio poder quanto ssoa dos filhos; 4.1 - O conceito de família e entes afins; 4.2 - $O$ dever de criação e educação; 4.3 - $O$ dever de rda; 4.4-O dever de representação e de assistência; 4.5 - Outras prerrogativas dos pais quanto à pessoa dos filhos; J pátrio poder quanto aos direitos patrimoniais; 5.1 - Do usufruto legal; 6- Da suspensão do pátrio poder; 7 - $\mathrm{Da}$ ituição e extinção do poder paternal.

Conceito e evolução

Segundo o testemunho dos historióufos, a mais antiga versão do pátrio poder á na patria potestas, cultivada já em época é-romana pelos hebreus, persas, gálatas $\mathrm{e}$ 1 geral pelos povos preclássicos consoante velações de Aristóteles (Ethic Nicômaco, II, 10) e de César (De bello gallico, VI, ), a que a generalidade dos romanistas se ferem ${ }^{1}$. Mas é em Roma, na expressão de aio, que a patria potestas se aperfeiçoa e se stitucionaliza definitivamente ${ }^{2}$.

E não discordam os tratadistas de que o atado jurisconsulto clássico referia-se aos cravos, os quais, segundo o mesmo relata, , parágrafo anterior de suas Institutas, tamim estavam sob a autoridade paternal, emJra em condições menos vantajosas que os !ii familias.

Dessa situação não dissente a doutrina umanista, isto é, de que filii e servi submeam-se ao poder do pater familias. Mas, de ual modo, não se discute que na atriarcalidade havia distinções entre a testas e o dominium relativamente ao esavo, pois o poder dominial para o último onsubstancia-se numa relação de direito atrimonial, na qual o servus não era senão um objeto do direito, como qualquer coisa, enquanto perante a potestade era o mesmo figurante de uma relação jurídica que lhe reconhecia a condição humana ${ }^{3}$.

Durante os primeiros séculos da idade romana, o poder paternal fez do chefe de família um sacerdote que presidia o culto familiar e um verdadeiro magistrado doméstico, que tomava as mais variadas decisões, sendo-lhe facultado executar sobre seus subordinados as penas mais rigorosas. Eram-lhe permitidos, v.g., o poder Vitae et necis, o de vendê-los a terceiros e o de abandoná-los a qualquer sorte, ou ainda, o de entregá-los como indenização noxae deditio. Esta situação imperou durante todo o período régio e, embora com moderações, no período republicano, quando o poder do chefe para determinar a morte do filho que estava sob sua potestade, devia contar com os parentes mais próximos ou com pessoas importantes, tais como senadores, consoante o relato de Aulus Gelius (Noctes Actices, V, 19) e o testemunho de autores da historiagrafia do $\mathrm{Di}$ reito 4 .

Todavia, a partir do Principado, foram relaxados muitos abusos do poder paternal, havendo Adriano, que subiu ao trono, no ano 117 d.C., expedido um edito que casti- 